\title{
Results of Periodontal Therapy Related to Tooth Type
}

\author{
S. P. Ramfjord, ${ }^{*}$ J. W. Knowles, E. C. Morrison, F. G. Burgett and R. R. Nissle
}

\begin{abstract}
CERTAIN TEETH or groups of teeth are prone to develop more severe periodontal destruction than other teeth in the same individuals. A test was made to assess if these same teeth or groups of teeth also respond less favorably to periodontal therapy than other teeth. Data from a longitudinal study of periodontal therapy for 78 patients over 8 years were analyzed with regard to effect of tooth types on treatment results. The response to periodontal treatment was only marginally related to tooth type with the most favorable responses in the maxillary and mandibular anterior teeth and the least favorable responses in the maxillary molars and bicuspids. Although a number of these differences were significant statistically, the actual values were too small to be of appreciable clinical significance. The overall prognosis for treatment of periodontal pockets apparently is good for all tooth types and this observation applies to moderate as well as to deep pockets.
\end{abstract}

Certain teeth or groups of teeth are prone to develop destructive periodontal disease earlier in life ${ }^{1}$ and continue to show more severe advancement of the disease with age $^{2}$ than other teeth in the same individuals or animals. ${ }^{3}$ The highest risk teeth in humans are the mandibular incisors and the maxillary molars, ${ }^{1}$ while for example in Beagle dogs ${ }^{3}$ the mandibular incisors are very resistant to this disease.

It is not known if the disease-prone teeth also have a less favorable response to therapy than the other teeth. Conceivably, tooth specific anatomical features and degrees of accessibility for therapy as well as oral hygiene could affect the prognosis of the therapy. It also may be that pockets of equal initial severity may respond to Jerapy differently in different parts of the mouth. In ther words, the yesponse to treatment of an $8 \mathrm{~mm}$ may be better in the anterior than the molar

in attempt to find an answer to these questions, om a longitudihal study reported elsewhere ${ }^{4}$ were naly with togard to impact of tooth type on the fesult blowing periog dontal treatment over time.

\section{MATERI LS AND METHODS}

Data from a longituo inal study of periodontal therapy involving 78 patients over 8 years ${ }^{4}$ were analyzed with regard to effect of tooth type on treatment results, with initial pocket depth as an expression of the severity of the disease. The dentition was divided into six tooth types (1) maxillary mólars, (2) mandibular molars, (3) maxillary bicuspids, (4) mandibular bicuspids, (5) maxillary anteriors, and (6) mandibular anteriors.

The experimental methodology and data management

* Department of Periodontics, University of Michigan, School of Dentistry, Ann Arbor, MI 48109. for these patients have been reported previously. ${ }^{4} \mathrm{Com}-$ bined data from the various experimental modalities of treatment were used for the present report. The analysis was based on means from six tooth groups for each patient.

Since it has been shown that pockets or crevices of initial equal depth from the four aspects of the tooth (mesial, distal, buccal and lingual) behave in a similar fashion after treatment, ${ }^{4}$ only mean values from all four surfaces are reported in the present paper.

The hypothesis of equal treatment effects for the six groups of teeth was tested by the analysis of variance. The F-test of the equality of mean changes between tooth types in three levels of severity of depth of pocket was carried out at each year following treatment. If the hypothesis of equal treatment effects was rejected at the 0.05 level of significance, Scheffe's procedure for multiple comparisons was used to determine which of the pairs of tooth groups differed. Ninety-five percent confidence intervals for mean changes were determined.

\section{RESULTS}

The mean reduction or increase in pocket depth and gain or loss of attachment are reported on the basis of grouping pockets in three categories of severity $(1-3 \mathrm{~mm}$, 4-6 $\mathrm{mm}$, and $7-12 \mathrm{~mm}$ ) and relating these three groups to the six tooth types.

For pockets or crevices 1 to $3 \mathrm{~mm}$ (Fig. 1), the differences in response to treatment over time appear to be small and of minor if any clinical significance. However, a number of these differences are statistically significant for some or all of the 8 years of follow up when Scheffe's procedure for multiple comparisons was used. For example, pocket depth was reduced significantly more and returned less for the mandibular anterior teeth than for the maxillary molars for all of the eight intervals. Other 
differences such as between the maxillary molars and the mandibular bicuspids were significant for seven of the eight intervals and between the maxillary molars and maxillary bicuspids for the last 4 years. In general, the maxillary molars represented the one type of teeth that most often responded significantly different in interaction with the other tooth types showing less short term reduction in pocket depth and more long term increase in depth beyond the baseline. There never was a significant difference in response between maxillary and mandibular bicuspids, while in a few instances the differences in response between the maxillary and the mandibular anterior teeth were significant.

With regard to attachment levels for the 1 to $3 \mathrm{~mm}$ pockets or crevices (Fig. 2), there are even less differences

\section{POCKET REDUCTION (Potient Meons) FOR INITIAL} POCKETS $1-3 \mathrm{~mm}$ BY TOOTH TYPE

$\mathrm{mm}$
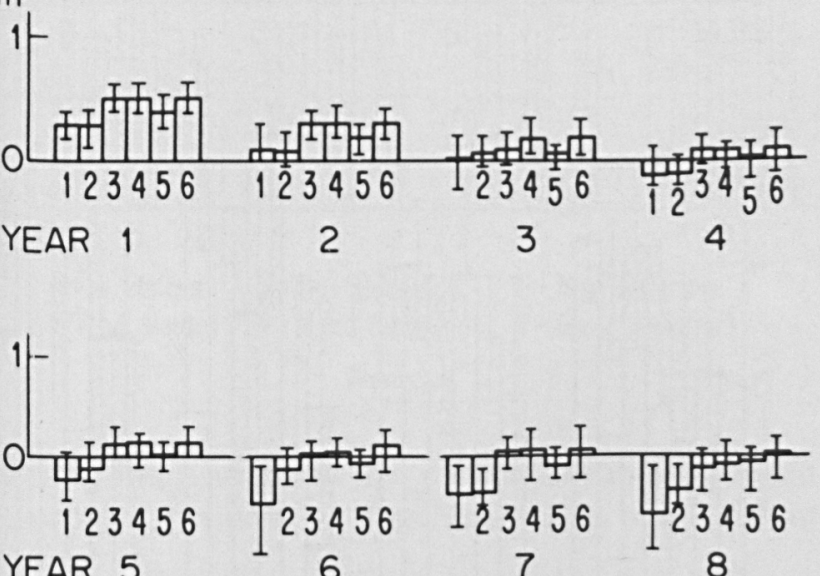

YEAR 5 6 7 8

$1=$ Max. Molars $\quad 3=$ Max. Bicuspids $5=$ Max. Anteriors 2- Mand. Molars $4=$ Mond. Bicuspids $6=$ Mand. Anteriors Figure 1

ATTACHMENT CHANGE (Potient Meons) FOR INITIAL POCKETS $1-3 \mathrm{~mm}$ BY TOOTH TYPE

$\mathrm{mm}$

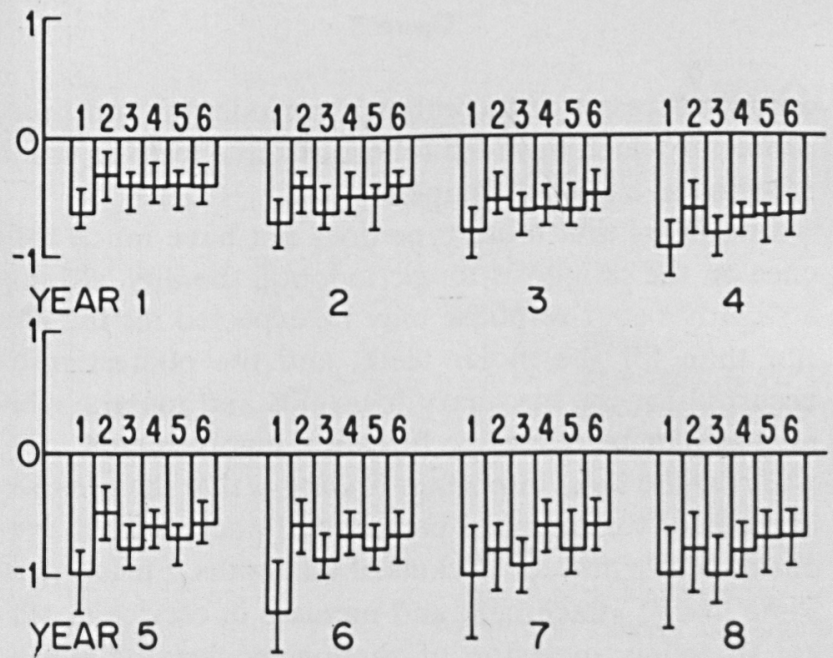

1-Max. Molors 3 -Max Bicuspids 5 - Mox. Anteriors

2-Mond. Molors 4 -Mond. Bicuspids 6 -Mond. Anteriors

Figure 2 in response among tooth groups than are found for pocket depth. Again, a few are statistically significant for year 4, 5, and 6 only, and practically all of these indicate more loss of attachment for the maxillary molars than for the other types of teeth. There is also a slight trend for more loss for the maxillary bicuspids than for the other teeth. Since this is true only for a few years and of small magnitude it apparently is not of any obvious clinical significance.

The reduction of 4 to $6 \mathrm{~mm}$ pockets over time is very similar for all tooth types (Fig. 3), although there is a trend toward greater reduction for the maxillary and mandibular anterior teeth than for the molars. These differences are statistically significant in the case of the mandibular anteriors for the first 4 years after treatment when Scheffe's procedure was applied, but after year four, none of the differences are significant.

The gain in attachment in pockets 4 to $6 \mathrm{~mm}$ deep (Fig. 4) is not significantly different among tooth types 1 year after treatment. However, from years 2 to 7 some differences are apparent.

The maxillary molars responded significantly less favorably than both the maxillary and mandibular anterior teeth. The anterior teeth gained and sustained attachment gain significantly better than any other group of teeth. In the Scheffe comparisons the maxillary bicuspids had the greatest number of significant losses compared with the other tooth types, followed by the maxillary molars.

Apparently the prognosis for gain of attachment in 4 to $6 \mathrm{~mm}$ pockets is best for anterior teeth and poorest for maxillary bicuspids and molars.

For 7 to $12 \mathrm{~mm}$ pockets (Fig. 5) there are no significant differences in pocket reduction related to tooth type 1

\section{POCKET REDUCTION (Patient Means) FOR INITIAL POCKETS 4-6 mm BY TOOTH TYPE}
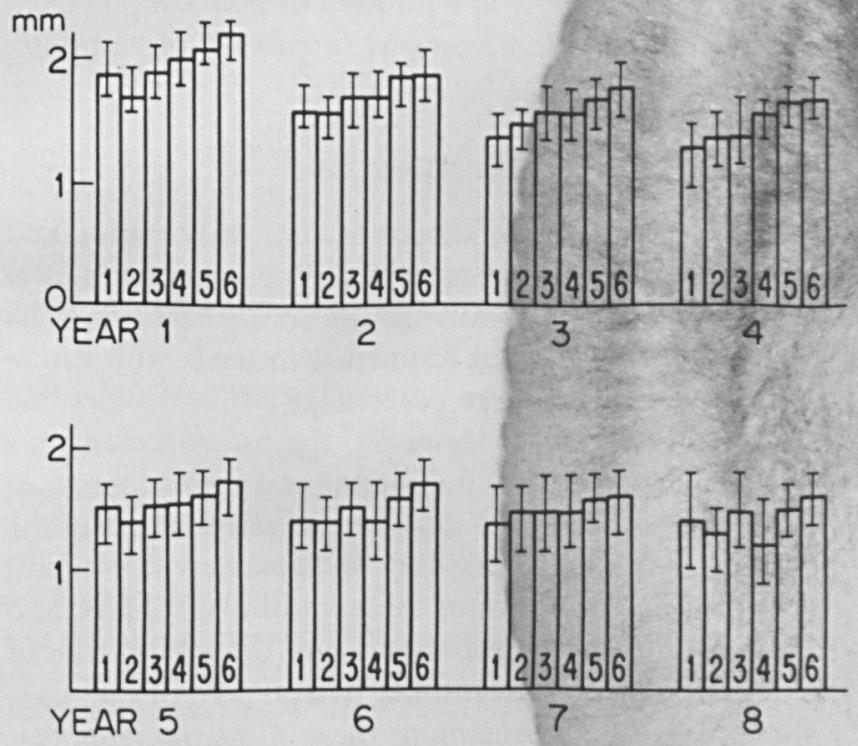

$1=$ Max. Molars $\quad 3=$ Max. Bicuspids $5=$ Max. Anteriors

$2=$ Mand. Molars $4=$ Mond. Bicuspids $6=$ Mond. Anteriors 
ATTACHMENT CHANGE (Potient Meons) FOR INITIAL POCKETS 4-6 mm BY TOOTH TYPE

$\mathrm{mm}$
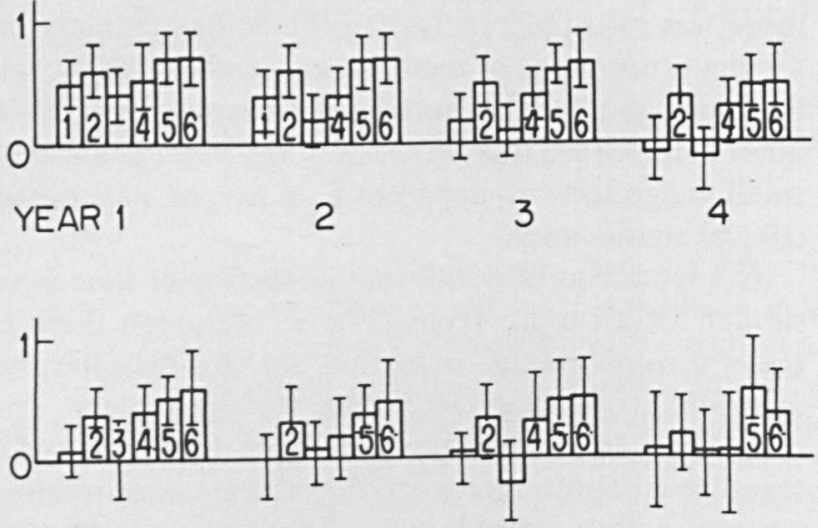

YEAR 5

6

7

8
POCKET REDUCTION (Potient Meons) FOR INITIAL POCKETS 7-12 mm BY TOOTH TYPE

$\mathrm{mm}$

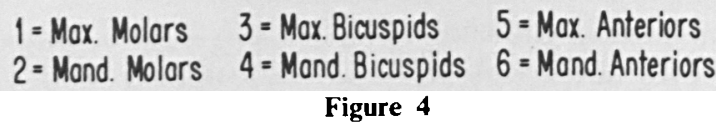

year after treatment. With time there is a trend towards more return of pocket depth in the molar than in the anterior regions, with significant differences between maxillary molars and mandibular anteriors for four of the eight intervals. There was never any significant difference between the maxillary and the mandibular anterior teeth, between the maxillary and mandibular bicuspids or between the maxillary and mandibular molars. Although there were a few statistically significant differences in response, beyond the differences between the maxillary molars and the mandibular anteriors, these sporadic differences were not consistent between any given tooth type and appear to be of questionable clinical signilicance.

1\% gains in attachment levels were not significantly diff amongtooth types for the 7 to $12 \mathrm{~mm}$ pockets (F) $)$. The jelat vely low number of such deep pockets may count for the variations in pattern of responses among the tooth types.

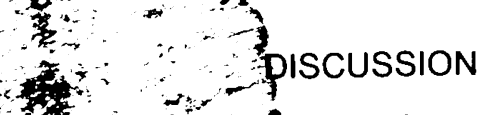

surprise rofst clinicians that only minor and consistefit differences in response to periodontal odvervid among the six tooth types. The Ifiestion is at happened to teeth with furcavement. A hrge percentage of the molars had involvement However, the measurements we ititiable are froth the mesial and distal aspects of mesiobuccal root of maxillary molars, and the buccal aspect of the mesial rotot of the mandibular molars, and from the most lingual prominence of the mesial root of the mandibular molats and the palatal root of the maxillary molars. With regards to these measurements furcation involvement did not appear to have much, if any, influence on the results. The main problem with deep furcation involvement has been development of perio-
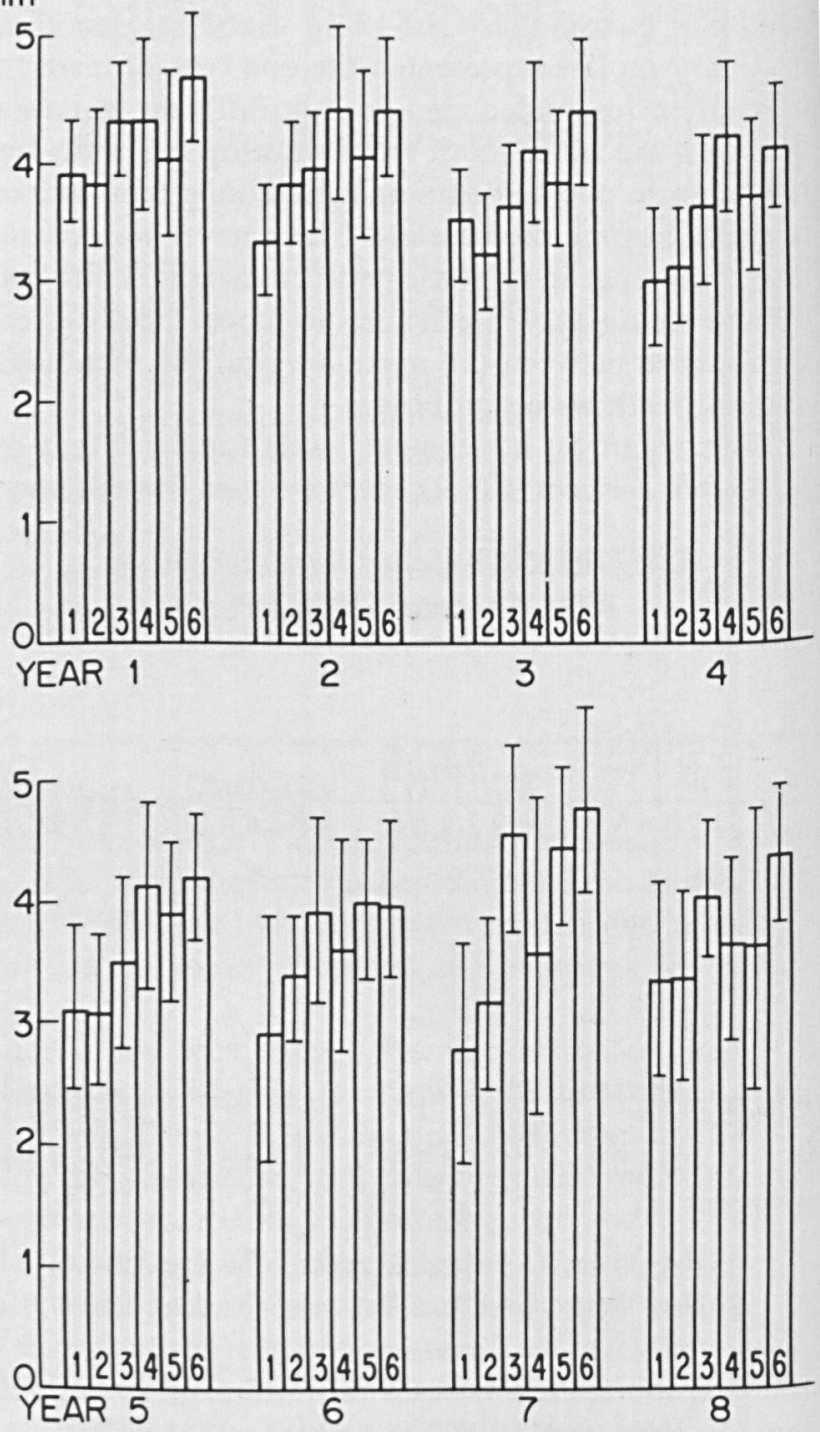

$1=$ Max. Molors $\quad 3=$ Max. Bicuspids $5=$ Max. Anteriors

$2=$ Mand. Molors $4=$ Mand. Bicuspids $6=$ Mand. Anteriors Figure 5

dontal abscesses and combined periodontal and pulpal problems which have led to loss of some teeth as will be reported in a separate paper.

It appears that tooth type does not have much influence on the prognosis for periodontal therapy, although a slightly better response may be expected for the anterior than for the molar teeth, and the poorest results occurred for the maxillary bicuspids and molars, which may in part be related to furcation involvements.

By far the most important finding is that the prognosis is good for treatment of periodontal pockets in all areas of the mouth and for pockets of all depths. Furthermore, some loss of attachment and increase in crevice depth is apt to follow inclusion of shallow pockets or gingival crevices $\leq 3 \mathrm{~mm}$ in periodontal surgery anywhere in the mouth, but this risk is slightly greater in the maxillary molar region than for the other tooth types. A disap- 


\section{ATTACHMENT CHANGE (Patient Meons) FOR INITIAL POCKETS $7-12 \mathrm{~mm}$ BY TOOTH TYPE}
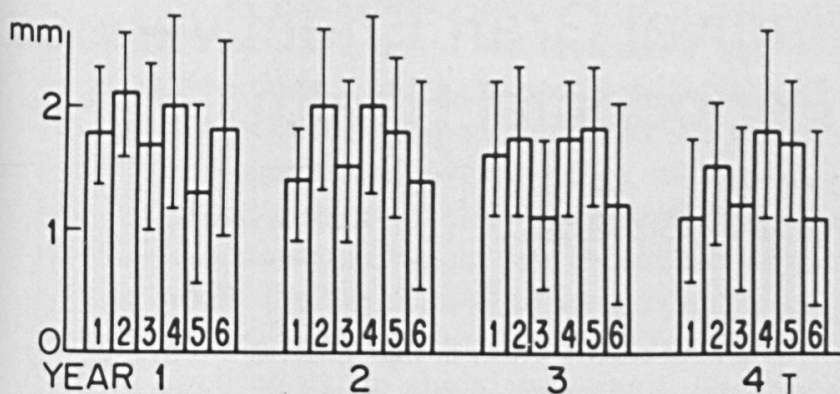

3
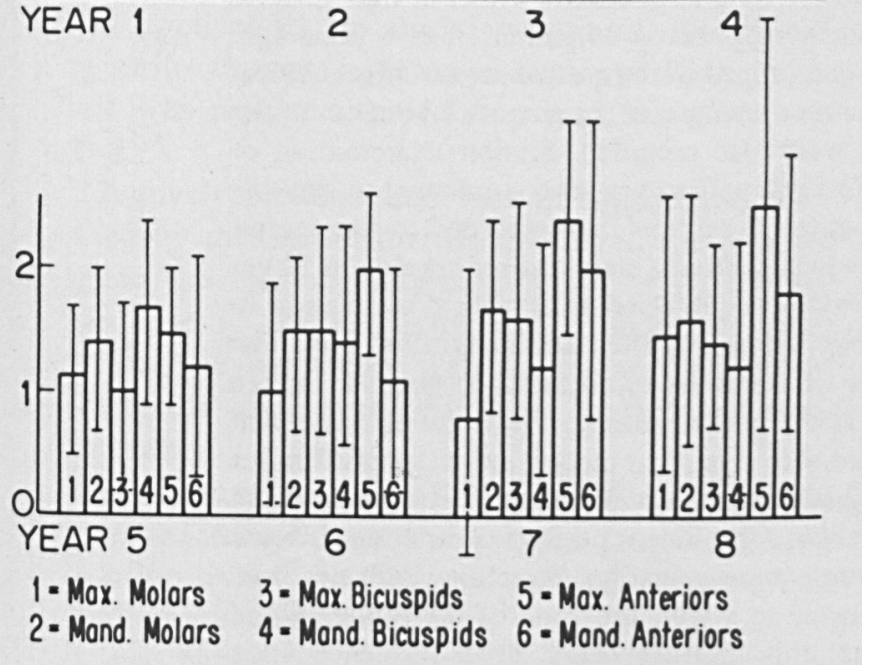

Figure 6

pointing observation was that we were not able to prevent progress of periodontal attachment loss over time in shallow crevices. A similar observation was made by Suomi et al. ${ }^{5}$

\section{CONCLUSIONS}

1. The response to periodontal treatment is only marginally related to tooth type with slight preference to the anterior teeth.

2. The prognosis for treatment of periodontal pockets is good for all tooth types, and this applies to moderate as well as to deep pockets.

\section{ACKNOWLEDGMENT}

The authors wish to thank Neil Wright for technical assistance in data management.

\section{REFERENCES}

1. Ramfjord, S. P.: The periodontal status of boys 11 to 17 years old in Bombay, India. J Periodontol 32: 237, 1961.

2. Schei, O., Waerhaug, J., Lovdal, A., and Arno, A.: Alveolar bone loss as related to oral hygiene and age. $J$ Periodontol 30: 7, 1959.

3. Sorensen, W. P.: The natural history of periodontal disease in Beagle dogs. Thesis. The University of Michigan, 1975.

4. Knowles, J. W., Burgett, F. G., Nissle, R. R., Shick, R. A., Morrison, E. C., and Ramfjord, S. P.: Results of periodontal treatment related to pocket depth and attachment level. Eight years. $J$ Periodontol 50: $225,1979$.

5. Suomi, J. P., Greene, J. C., Vermillion, J. R., Doyle, J., Chang, J. J., and Leatherwood, E. C.: The effect of controlled oral hygiene procedures on the progression of periodontal disease in adults: Results after third and final year. $J$ Periodontol 42: 152, 1971.

Send reprint requests to: Dr. S. P. Ramfjord, Department of Periodontics, University of Michigan School of Dentistry, Ann Arbor, MI 48109.

\section{Announcement}

\section{UNIVERSITY OF MARYLAND SCHOOL OF DENTISTRY}

The School of Dentistry, University of Maryland announces the following course:

Title: Advanced Clinical Periodontics for the General Practitioner-III

Dates: September 4, 11, 18, 25, October 2, 16, 30, November 6, 1980 (1:00 P.M. to 5:00 P.M. each day)

Faculty: John J. Bergquist, D.D.S., M.S., Professor and Chairman, and ANDrew Allen, D.M.D., Department of Periodontics, School of Dentistry, University of Maryland.

This course consists of seminars and clinical participation in advanced periodontal surgery procedures. Perio I and Perio II are prerequisites. Patients and instruments furnished by the Dental School. Limited to 6 registrants.

For Further information contact Continuing Education Program, School of Dentistry, University of Maryland, Baltimore, MD 21201 (301)528-7146.

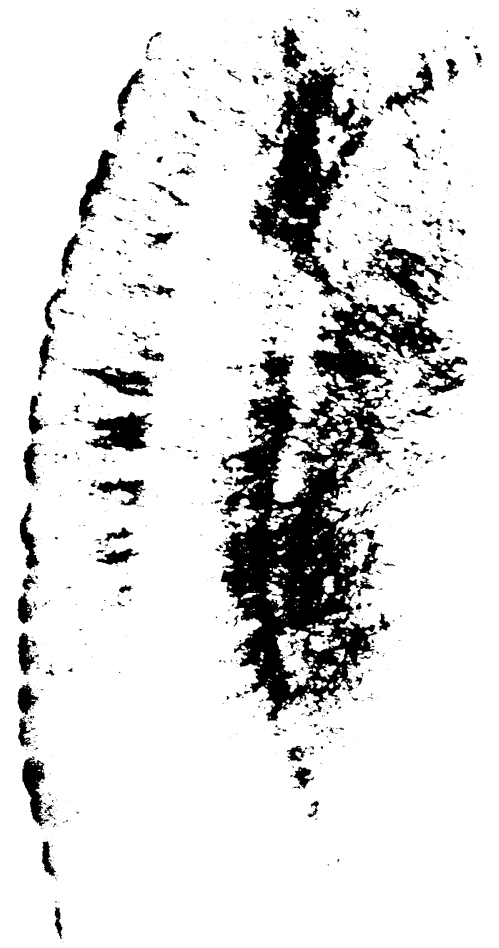

